\title{
Democracia e direitos humanos: aprendizagens para a educação em direitos humanos ${ }^{1}$
}

- Democracia y derechos humanos: aprendizajes para la educación en derechos humanos

- Democracy and human rignts: learningfor human
rightseducation

O correr da vida embrulha tudo, a vida é assim: esquenta e esfria, aperta e daí afrouxa, sossega e depois desinquieta. O que ela quer da gente é coragem. O que Deus quer é ver a gente aprendendo a ser capaz de ficar alegre a mais, no meio da alegria, e inda mais alegre ainda no meio da tristeza.

João Guimarães Rosa, Grande Sertão: Veredas (2019, p. 230)

\section{Paulo César Carbonari²}

Resumo: No artigo reflete-se sobre a relação entre democracia e direitos humanos considerando os desafios para a educação em direitos humanos de modo contextualizado e em perspectiva emancipadora e libertadora. Inicia-se com uma análise, ainda que suscinta dos traços gerais do contexto que se caracterizam pelo ataque aos direitos humanos e à democracia. Em seguida, busca-se em Theodor Adorno, que se perguntou sobre a Educação após Auschwitz, subsídios históricos para enfrentar a questão no âmbito da educação em direitos humanos. Nele inspirado, busca-se esboçar aprendizagens a serem levadas em conta na perspectiva da educação em direitos humanos como subsídio para o

1 Esta é uma versão revisada e reestruturada de texto publicado nos anais do XX Endipe (2020) - ver CRUZ; FERNANDES, FONTOURA, MESQUITA, 2020: Versão em vídeo disponível em: www.youtube.com/watch?v=4nep3SGfgKo. Acesso em 20 jul. 2021

2 Doutor em filosofia pela Unisinos; professor no Instituto Superior de Filosofia Berthier (IFIBE-RS), de 1991 a 2019; membro do Grupo de Estudo e Pesquisa sobre Educação em Direitos Humanos no IFIBE; membro da coordenação nacional do Movimento Nacional de Direitos Humanos (MNDH) e presidente do Conselho Estadual de Direitos Humanos do Rio Grande do Sul (CEDH-RS, 2014 a 2020). 
fortalecimento da democracia e a realização dos direitos humanos.

Palavras-chave: Democracia. Direitos humanos. Educação em direitos humanos. Adorno.

Resumen: Reflexiona se, en el artículo, sobre la relación entre democracia y derechos humanos considerando los desafíos para la educación en derechos humanos de modo contextualizado y con una perspectiva emancipadora y liberadora. Empieza con un análisis, aunque haga unresumen de los rasgos generales, del contexto que se caracteriza por el ataque a los derechos humanos y la democracia. Luego, se va a Theodor Adorno, quien preguntó sobre Educación después de Auschwitz. Se hace una búsqueda de subsidios históricos para enfrentar el tema en el área de educación en derechos humanos. Inspirándonos en ella, buscamos perfilar aprendizajes a tener en cuenta en la perspectiva de la educación en derechos humanos como un subsidio para el fortalecimiento de la democracia y la realización de los derechos humanos.

Palabras clave: Democracia. Derechos humanos. Educación en derechos humanos. Adorno.

\begin{abstract}
This article reflects on the relationship between democracy and human rights considering the challenges for human rights education in a contextualized way and in an emancipatory and liberating perspective. It begins with an analysis, although it summarizes the general features of the context that are characterized by the attack on human rights and democracy. Then, Theodor Adorno, who asked about Education after Auschwitz, is searched for historical subsidies to face the issue in the area of human rights education. Inspired by his, we seek to outline learning to be taken into account in the perspective of human rights education as a subsidy for the strengthening of democracy and the realization of human rights.
\end{abstract}

Keywords: Democracy. Human rights. Human rights education. Adorno.

Ítalo Calvino, em As Cidades Invisíveis (1972), traz o diálogo entre Marco Polo e Kublai Kahm que se segue a Aglaura. O grande Kahm comenta que: "- Entretanto, construí na minha mente um modelo de cidade do qual extrair todas as cidades possíveis". Segue: "- Ele contém tudo o que vai de acordo com as normas. Uma vez que as cidades que existem se afastam da norma em diferentes graus, basta prever as exceções à regra e calcular as combinações 
mais prováveis" (1990, p. 67). Em resposta Marco Polo sugere: "- Eu também imaginei um modelo de cidade do qual extraio todas as outras". E segue:"-É uma cidade feita só de exceções, impedimentos, contradições, incongruências, contrassensos. [...]" (1990, p. 67).

O embate entre o grande Kahm e Marco demonstra uma tensão que também é própria da democracia, dos direitos humanos e da educação em direitos humanos: fazer da realidade a aplicação de um modelo pronto no qual o estar de acordo com as normas, aderir ao sistema e agarrar-se à "lei e a ordem" é o que se há de fazer dos direitos humanos numa posição regulatória; ou ser construtor de realidades que rompem modelos, estar do lado das incongruências e, como sugere Henri Lefebvre, "abrir o pensamento e a ação na direção da possibilidade" (2001, p. 9), para fazer da democracia, dos direitos humanos e da educação em direitos humanos recursos de emancipação e de libertação. Acreditamos mais na tendência ao modo Marco, bem como a traduziu Manu Chao: "clandestino, ilegal"."

Fazer educação em direitos humanos, neste sentido, exige exatamente fazer uma profunda leitura dos contextos nos quais se está inserido, de modo que não se apliquem modelos - que, por mais perfeitos que sejam, são sempre modelos - prontos ou mesmo que a ela sirva para consolidar modos de vida fechados e que sejam repetitivos, miméticos e ajustadores das práticas. O que uma sociedade democrática que assume os direitos humanos como experiência comum é exatamente ter na educação em direitos humanos aliado para construir esta experiência no cotidiano da vida dos sujeitos/as que dela são participantes e estão em disputa nos processos históricos nos quais são vividas. Uma sociedade democrática no profundo sentido substantivo (para além do formalismo das regras liberas do jogo) é aquela que sabe lidar com as exceções, os impedimentos, as contradições, as incongruências, os contrassensos. ${ }^{4}$ E para lidar com estas dinâmicas há que ser educado e que se educar.

Difícil de caracterizar de modo sucinto o tempo que nos é dado viver em nosso Brasil. Ensaiamos alguns traços. Ainda assim, podemos dizer que tanto a democracia, quanto os direitos humanos e a educação em direitos humanos estão hoje "sob ataque", de cercamento, de destruição - muito além de retrocesso. $\mathrm{O}$ capitalismo atual parece não mais precisar de valores como

3 Ver na versão playing for change: www.youtube.com/watch?v=WvPmNdNc2-E. Acesso em: 20 jul. 2021.

4 Tratamos mais a fundo sobre o tema entre outros, em "Democracia e Direitos Humanos: reflexões para uma agenda substantiva e abusada" (2008, p. 10-27). 
a democracia e os direitos humanos. Cresce cada vez mais a presença do modelo de mercado, da empresa, como aquele a ser aplicado para o Estado, para a vida em comum e individual (selfmademan), o "individuo proprietário" (de si e de tudo o que puder), e inclusive uma "inversão dos direitos humanos"s que leva inclusive a um uso dos direitos humanos para o interesse privado. $O$ fato é que os direitos humanos e a democracia não chegaram para o cotidiano da vida das maiorias; 0 que chega todos os dias a elas é a lei e a ordem em práticas "necropolíticas".

O ultra neoliberalismo se caracteriza como a forma-de-vida do capitalismo (que já não é só um modo de produção) com centralidade no mercado em busca incessante de valor, mas sem produção ${ }^{6}$ e financeirização de tudo pela força da especulação financeira. $\mathrm{O}$ "modelo empresa" se reivindica para tudo, inclusive para os indivíduos, de modo que passam a ser empresários de $\mathrm{si}^{7}$. A vigência dos interesses individuais (do individualismo egoísta) ${ }^{8}$ instala uma concorrência generalizada na qual cada outro é transformado em potencial (senão real) inimigo, mais do que adversário, contra o qual lutar o tempo todo, mantendo a distância necessária para que, no melhor do possível, haja a tolerância baseada no medo (medo de perder tudo, de não ganhar ao máximo, de ser tomado pelos/as outros/as). A concentração da riqueza e o crescimento da desigualdade ${ }^{9}$, da irresponsabilidade social e ambiental ${ }^{10}$ e a quebra da solidariedade social são disso consequências diretas.

Os/as principais afetados/as, os/as mais vulnerabilizados/as, os/as mais precarizados/as, são "culpados/as" de sua própria condição, que chamamos de "Racionalidade Vitimária" em nossa tese de doutoramento (2015) e cujas características principais são: (1) naturalização da condição de vítima: vítimas são necessárias e inevitáveis; (2) culpabilização daqueles/as que estão na condição de vítimas: vítimas merecem ser vítimas e devem "pagar" por sua culpa; (3) impotência daqueles/as que estão na condição de vítimas: vítimas, por elas mesmas, não podem deixar de ser vítimas [adubando um terreno fértil para uma] racionalidade fascista.

Como sugere Franz Hinkelammert em "La inversión de los derechos humanos” (2003, p. 75-120).

6 Ladislau Dowbor defende que vivemos A Era do Capital improdutivo (2017, p. 246).

7 Foucault dizia, em Nascimento da biopolítica, que a estratégia neoliberal é de construir uma "formalização da sociedade com base no modelo da empresa" (2008, p. 222). O ser humano é reduzido: "Ohomo oeconomicus é um empresário, e um empresário de si mesmo" (2008, p. 311).

8 Ayn Rand, em Egoismo como Virtude (1991) é um exemplo.

9 Ver o relatório Tempo de Cuidar da Oxfam disponível em https://oxfam.org.br/justica-social-e-economica/forum-economico-de-davos/tempo-de-cuidar/. Para o Brasil ver www.oxfam.org.br/pais-estagnado. Acesso em: 20 jul. 2021

10 O relatório do Painel sobre Mudanças Climáticas (IPCC/ONU) (www.ipcc.ch/sr15/) é forte indicador desta questão. Um resumo dos dados atualizados se encontra em www.bbc.com/portuguese/geral-46424720. Acesso em: 20 jul. 2021 
Ela é funcional ao ultraneoliberalismo e se caracteriza por ser: racista (nega a alteridade, que é ameaça); dogmática (simplificadora da realidade, "falência da crítica"); "neutra (se apresenta "sem ideologia"); autoritária (antidemocrática, não suporta sequer a democracia liberal e faz governo a partir do medo); fatalista ("naturalização" das relações e dos acontecimentos); antiutopista (rouba o direito de sonhar, o desejo do impossível); e anti-intelectualista (recusando-se compreender o que está acontecendo, invocando logo saídas e soluções). Ela se orienta pela atitude de "douta ignorância" (não aquela do cusano) que dá respostas fáceis e superficiais: é a elevação do senso comum ao grau de ciência ou, no movimento contrário, a invocação do tecnocrático como solução rápida que dispensa o engajamento da responsabilidade coletiva. Se orienta ao modo Ismênia, a irmã de Antígona de Sófocles, que defendia que o impossível nem sequer pode ser tentado.

O populismo ${ }^{11}$ de direita se caracteriza por ser ultraconservador. A direita teria capturado a luta antissistêmica? A este respeito a filósofa alemã Carolin Emcke é enfática: "O problema dos últimos anos foi a falta de desejo político. Parece que só a extrema direita tem uma utopia. É uma utopia regressiva, de morte e destruição, mas utopia. Conservadores e social-democratas não têm nenhuma"12. A política é transformada numa guerra permanente contra os adversários numa dinâmica de mobilização dos adeptos fieis por meio da "guerra cultural"13. que é sintoma de uma crise de alternativas, forma de moralização, de demonização do outro, das diversidades, da política. Isto significa que o"fazer política"14 é menos cumprir um programa de governo e mais um manter-se mobilizado e mobilizar permanentemente os próprios seguidores, num claro desmonte dos processos democráticos e participativos.

Qual educação em direitos humanos nesse contexto? Há educação em direitos humanos neste contexto? Será ela um modo de introjetar disciplinas próprias da compreensão dos direitos humanos do tipo regulatório e repressivo, o que seria por si só já um contrassenso, mas uma prática perfeitamente possível num contexto como o que vivemos? Haveria alternativas? Em outras palavras, qual educação em direitos humanos é possível em tempos de vigên-

11 Necessário retomar o debate sobre o tema do populismo em geral e do populismo de direita em particular.

12 Ver entrevista a El País, de 12/11/2019. Disponível em: https://brasil.elpais.com/brasil/2019/11/01/cultura/1572612640_359278.html?\%3Fssm=FB_BR_CM\&hootPostID=510df47c4f698da62cc2b062beb6db21. Acesso em: 20 jul. 2021

13 Em entrevista à Nexo, "O que é 'guerra cultural'. E por que a expressão está em alta", feita por Juliana Sayuri, e publicada em10/03/2019, ver www.nexojornal.com.br/ expresso/2019/03/10/O-que-\%C3\%A9-\%E2\%80\%98guerra-cultural\%E2\%80\%99.-E-por-que-a-express\%C3\%A3o-est\%C3\%A1-em-alta.. Acesso em: 20 jul. 2021

14 Esta é a análise de Roberto Dutra Torres Jr, em entrevista ao IHU OnLine, de 06/01/2020, disponível em www.ihu. unisinos.br/159-noticias/entrevistas/595340-o-ponto-mais-importante-desse-primeiro-anode-governo-e-a-forca-desse-modelo-de-fazer-politica-entrevista-especial-com-roberto-dutra . Acesso em: 20 jul. 2021 
cia da racionalidade autoritária fascista? Esta é uma outra forma de fazer a pergunta.

O texto Educação após Auschwitz, Theodor Adorno ${ }^{15}$ diz que "a civilização, por seu turno, origina e fortalece progressivamente o que é anti-civilizatório" (2003, p. 120). Opor-se a isso "tem algo de desesperador" visto que "a barbárie encontra-se no próprio princípio civilizatório" (2003, p. 120). O que "apavora" é que "a barbárie continuará existindo enquanto persistirem no que tem de fundamental as condições que geram esta regressão" (2003, p. 119). Esta posição está próxima daquela de Walter Benjamin na VII das teses Sobre o Conceito de História (1940): "Nunca há um documento de cultura que não seja, ao mesmo tempo, um documento da barbárie" (2005, p. 70). E também próxima do que é construído na Dialética do Esclarecimento (1947), que redigiu com Horkheimer. Isso significa que a "regressão à barbárie" não é apenas uma ameaça, mas é uma realidade. Nisso há uma atualidade e uma consistência difíceis de serem suplantadas pelos progressismos ou pela excessiva confiança no humanismo que, por vezes, cega ao que efetivamente vai acontecendo. Como diz: "Isto [milhões de pessoas inocentes foram assassinadas de uma maneira planejada] não pode ser minimizado por nenhuma pessoa viva como sendo um fenômeno superficial, como sendo uma aberração no curso da história, que não importa, em face da tendência dominante do progresso, do esclarecimento, do humanismo supostamente crescente" (2003, p. 120).

O desejo de Adorno, expresso já na primeira frase de seu texto, o de que a exigência primeira para a educação é que "Auschwitz não se repita" (2003, p. 119). Para isso, a convocação feita por ele vai no sentido da superação do que chamou da "ausência de consciência" (2003, p. 121) e, depois, de "consciência coisificada" (Verdinglichung): "No começo as pessoas desse tipo se tornam por assim dizer iguais a coisas. Em seguida, na medida em que o conseguem, tornam os outros iguais a coisas" (2003, p. 130). No texto $A$ filosofia e os professores, publicado na mesma coletânea pela Paz e Terra, Adorno diz que "Uma das características da consciência coisificada e manter-se restrita a si mesma, junto a sua própria fraqueza, procurando justificar-se a qualquer custo" (2003, p. 71).

Ocorre uma espécie de naturalização do "ser-assim": "Esta [a consciência coisificada] é, sobretudo, uma consciência que se defende em relação a qualquer vir-a-ser, frente a qualquer apreensão do próprio condicionamento, impondo como sendo absoluto o que existe de um determinado modo"

15 Resultante de palestra feita por Theodor W. Adorno pela rádio de Hessen, em 18 de abril de 1965. Foi publicado em Zum Bildungsbegriff der Gegenwart, em Frankfurt, em 1967. No Brasil foi publicado em Educação e Emancipação (1995). 
(2003, p. 132). Firma-se a indiferença e da falta de empatia: "[...] se as pessoas não fossem profundamente indiferentes em relação ao que acontece com todas as outras, excetuando o punhado com que mantem vínculos estreitos e possivelmente por intermédio de alguns interesses concretos, então Auschwitz não teria sido possível, as pessoas não o teriam aceito" (2003, p. 134); afirma-se o individualismo: "A frieza da mônada social, do concorrente isolado, constituía, enquanto indiferença frente ao destino do outro, o pressuposto para que apenas alguns raros se mobilizassem. Os algozes sabem disto; e repetidamente precisam se assegurar disto" (2003, p. 134) e a neutralidade: "Quem ainda insiste em afirmar que o acontecido nem foi tão grave assim já está defendendo o que ocorreu, e sem dúvida seria capaz de assistir ou colaborar se tudo acontecesse de novo" (2003, p. 136).

' A superação destas condições se fará pela formação da consciência para a reflexão e a autorreflexão crítica e para a resistência (2003, p. 122), já que o "único poder efetivo contra o princípio de Auschwitz seria a autonomia, para usar a expressão kantiana; o poder para a reflexão, a autodeterminação, a não-participação" (2003, p. 125). A educação, ainda que limitada, tem uma responsabilidade fundamental de ajudar a "não esquecer" ou de alimentar a memória dos acontecimentos, passados e atuais, como formação de consciência, mas também de promoção da autorreflexão crítica, de modo a que os/ as sujeitos/as se situem e se posicionem para resistir à barbárie que segue presente, o que certamente também inclui sua denúncia.

Adorno inspira a pensar que os tempos autoritários não são obra passada e nem lugares ou situações estanques. Eles são parte do processo civilizatório, já que a barbárie não lhe é seu oposto e sim sua outra face constitutiva. Este é um grande desafio para a educação em geral e para a educação em direitos humanos: saber que, por mais que se eduque, sempre estará posta a tarefa de seguir educando; saber que, por mais que humanize, sempre estará posto o desafio de humanizar; saber que, ao formar sujeitos/as, sempre estará posta a exigência de formar sujeitos de direitos. Este exercício é uma espécie de "querer o impossível"16.

A educação em direitos humanos há que ajudar a entender a perversidade que faz com que, ainda que não suprima os direitos de direito, os destrói de fato. Esta contradição mais contundente do fascismo atual é o que desafia de modo ainda mais difícil. Os direitos humanos não foram retirados da Cons-

16 Como sugere a respeito de Adorno o que propõe Vladimir Safatle no controverso Dar corpo ao impossível (2019). 
tituição. O Programa Nacional de Direitos Humanos (PNDH-3) ${ }^{17}$ e o Plano Nacional de Educação em Direitos Humanos (PNEDH) ${ }^{18}$, o Parecer e a Resolução do Conselho Nacional de Educação com as Diretrizes Nacionais para a Educação em Direitos Humanos ${ }_{1}^{19}$ seguem vigentes, mas não para serem realizados.

A aprendizagem do como promover a formação da consciência para a reflexão e a autorreflexão crítica e para a resistência (2003, p. 122) é o desafio de fundo para promover o que Adorno classifica como o "único poder efetivo contra o princípio de Auschwitz", a autonomia, que ele traduz como "o poder para a reflexão, a autodeterminação, a não-participação" (2003, p. 125). Aqui está um programa de ação para a educação em direitos humanos que é oportuno para o tempo em que vivemos. Trata-se de insistir e fazer processos, ainda que em contra a tudo o que se põe como apropriado. As três características da autonomia sugeridas por Adorno são fundamentais para a educação em direitos humanos como agenda positiva.

Trata-se de desenvolver a reflexão, a autodeterminação e a não-participação. Juntas, oferecem subsídios para enfrentar o principal problema que é a "consciência coisificada", promovendo aquilo que Paulo Freire chama de "ontológica e histórica vocação dos homens [e mulheres] - a de SER MAIS" $(1975$, p. 45). A reflexão exige o desenvolvimento de modos diversos de "conscientização" como aprendizagem da liberdade e do seu exercício nas relações entre distintos. É ela que alimenta posturas que se recusam a aceitar o que é imposto como normal e, sobretudo, a desenvolver a capacidade de crítica como atitude e como competência. A autodeterminação exige que se trabalhe a independência e o posicionamento próprio. A autodeterminação é consciência do limite e da relação, posição firme na dinâmica de convivência e de construção do comum, que preserva a singularidade, mas que não se esvai em individualismos egoístas identitários - e não se confunde com o empreendedor de si. A não-participação, expressa pelo negativo, é a que se traduz em resistência, em oposição, em força destituinte, em recusa à colaboração. Esta é a qualidade mais difícil da autonomia em sociedades de massa e totalitárias, visto que requer ir contra ao modo convencional de fazer e de ser. Como bem lembra Primo Levi, em É isto um homem? (1958), "[...] mas ainda nos resta uma

17 É o terceiro PNDH, publicado pelo Decreto Federal nº 7.037, de 21/12/2009. Substitui o PNDH-2, que era de 2002 (Decreto Federal no 4.229, de 13/05/2002). A única coisa que foi revogada foi o artigo $4^{\circ}$ que previa um Comitê de Acompanhamento e Monitoramento (Decreto Federal no 10.087, de 05/11/2019).

18 Elaboração iniciada em 2003 com a instalação do Comitê Nacional de Educação em Direitos Humanos, publicado em 2006. Ironicamente foi republicado em 2018 pelo então Ministério dos Direitos Humanos (www.mdh.gov.br/ navegue-por-temas/educacao-em-direitos-humanos/DIAGRMAOPNEDH.pdf).

19 Trata-se de decisão do Pleno do Conselho Nacional de Educação (CNE), através do Parecer CNE/Pleno n 8, de 06/052012 e da Resolução CNE/Pleno no 1, de 30/052012 (www.mdh.gov.br/navegue-por-temas/educacao-em-direitos-humanos/DiretrizesNacionaisEDH.pdf). 
opção. Devemos nos esforçar por defendê-la a todo custo, justamente porque é a última: a opção de recusar nosso consentimento" (1988, p. 55). Ela não significa anomia ou afastamento dos espaços democráticos e participativos no sentido lato, mas na denúncia dos falsos processos participativos e investimento na construção da participação como efetividade e engajamento.

A possibilidade de desenhar modos outros de ser e de viver que escapem à coisificação e à massificação que alimentam o abandono da reflexividade e da autodeterminação se colocam como tarefa pedagógica e política para que a educação em direitos humanos se faça educadora e formadora de sujeitos e sujeitas de direitos humanos. Assim que, a promoção da educação em direitos humanos segue sendo encorajamento a ser mais ao modo do querer em detrimento do modo do dever, ou a fazer o dever ao modo do querer, visto que é porque queremos direitos que concordamos com obrigações, não o contrário. Aprender esta máxima anti-conservadora por excelência é um dos principais desafios. Por isso é que a tarefa é aprender que democracia, direitos humanos e educação em direitos humanos fazem sentido como prática, como processo, como aprendizagem: aprendemos a ser democráticos, aprendemos direitos humanos, nos educamos em direitos humanos, não como espontaneidade, mas como obra comum, em comum, permanente, intencional, sistemática, como experiência - no sentido de Walter Benjamin pessoal e coletiva emancipadora.

Enfim, trata-se de aprender e seguir ensinando que os direitos humanos são a afirmação de que a humanidade é um bem comum a todos/as é primordial para a educação em direitos humanos. A humanidade que está em cada ser humano é exatamente a mesma: são iguais. Mas, ainda que a humanidade que está em cada um/a seja a mesma, o modo como ela se apresenta é singular: humanos/as são únicos/as, distintos. Por isso, aprender a não-discriminação para, além de não ser racista, ser antirracista, como sugere Angela Davis. ${ }^{20}$ Mas é também aprender a querer o usufruto de todos os bens e as condições necessárias ao bem-viver (o direito à saúde, à educação, à cultura, à moradia, à alimentação saudável, à liberdade de expressão, à mobilidade, a não sofrer violência, a seguir a religiosidade que quiser, ao trabalho decente, à remuneração justa, ao lazer, à previdência e assistência social, enfim...). Por isso, aprender a se opor a todas as formas de imposição de austeridades des-

20 Ver: https://blogdaboitempo.com.br/2017/07/28/angela-davis-construindo-o-futuro-da-luta-contra-o-racismo/. Acesso em: 20 jul. 2021 
truidoras de direitos e de vidas.

Inspirada em Paulo Freire, Bell Hooks traduz o que dissemos, ainda que noutros contextos, por uma "pedagogia engajada" num processo através do qual o desafio é educar "para transgredir". No final da abertura de seu livro Ensinando a transgredir, Bell Hooks $(2013,24)$ pede que todos/as "[...] abram a cabeça e o coração para conhecer o que está além das fronteiras do aceitável, para pensar e repensar, para criar novas visões", e completa, "celebro um ensino que permita as transgressões - um movimento contra as fronteiras e para além delas. É esse movimento que transforma educação na prática da liberdade".

\section{Referências}

ADORNO, Theodor W. "Educação após Auschwitz". In: Educação e Emancipação. 3. ed. Trad. Wolfgang Leo Maar. São Paulo: Paz e Terra, 2003, p. 119-138.

ADORNO, Theodor W.; HORKHEIMER, Max. Dialética do Esclarecimento. Fragmentos filosóficos. Trad. Guido Antônio de Almeida. 3. ed. Rio de Janeiro: Zahar, 1991

BENJAMIN, Walter. Sobre o Conceito de História. In: LÖWY, Michael. Walter Benjamin: aviso de incêndio. Uma leitura das teses Sobre o Conceito de História. Trad. W. N. Caldeira Brandt [Trad. das teses por J. M. Gagnebin e M. L. Müller]. São Paulo: Boitempo, 2005.

CALVINO, Ítalo. As cidades invisíveis. 2. ed. Trad. Diogo Mainardi. São Paulo: Companhia das Letras, 1990.

CARBONARI, Paulo César. A potencialidade da vítima para ser sujeito ético: construção de uma proposta de ética a partir da condição da vítima. Tese. Doutorado em Filosofia. Universidade do Vale do Rio dos Sinos (Unisinos). São Leopoldo, 2015.

CARBONARI, Paulo César. Democracia e direitos humanos: reflexões para uma agenda substantiva e abusada. In: BITTAR, Eduardo C. B.; TOSI, Giuseppe (org.). Democracia e educação em direitos humanos numa época de insegurança. João Pessoa: UFPB, 2008. p. 10-27. Disponível em: http://www.cchla. ufpb.br/ncdh/wp-content/uploads/2015/11/DEMOCRACIA.DH_.EPOCA_. INSEGURAN\%C3\%87A.pdfAcesso em 15 jul. 2021.

CRUZ, Giseli Barreto da et. al (org.). Didática(s) entre diálogos, insurgências e 
políticas. Rio de Janeiro/Petrópolis: Faperj; CNPq; Capes; Endipe /DP et al., 2020 - publicação eletrônica.

DOWBOR, Ladislau. A era do capital improdutivo: por que oito famílias têm mais riqueza do que a metade da população do mundo? São Paulo: Autonomia Literária, 2017.

FOUCAULT, M. Nascimento da Biopolítica. Trad. Eduardo Brandão. São Paulo: Martins Fontes, 2008.

FOUCAULT, M. O anti-Édipo: uma introdução à vida não fascista. Trad. Fernando José Fagundes Ribeiro. Cadernos de Subjetividade. Núcleo de Estudos e Pesquisas da Subjetividade do Programa de Estudos Pós-Graduados em Psicologia Clínica da PUC-SP, São Paulo, v. 1, n. 1, p. 198-200, 1993.

FREIRE, Paulo. Pedagogia do Oprimido. 2. ed. Rio de Janeiro: Paz e Terra, 1975. HINKELAMMERT, Franz. El sujeto y la lei. El retorno del sujeto reprimido. Heredia, Costa Rica: EUNA, 2003.

HOOKS, bell. Ensinando a transgredir: a educação como prática da liberdade. Trad. M. B. Cipolla. São Paulo: WMF Martins Fontes, 2013.

LACLAU, Ernesto. A razão populista. Trad. C.E. Marcondes de Moura. São Paulo: Três Estrelas, 2013.

LEFEBVRE, Henri. O direito à cidade. Trad. Rubens Eduardo Frias. São Paulo: Centauro, 2001.

LEVI, Primo. É isto um homem? Trad. Luigi Del Re. Rio de Janeiro: Rocco, 1988.

ORNELAS ROSA, Pablo (org.). Fascismo tropical: uma cibercartografia das novíssimas direitas brasileiras. Vitória: Editora Milfontes, 2019

RAND, Ayn. A virtude do egoísmo. Trad. OnLine Assessoria de Idiomas. Rev. W. Ling e C. Mendes Prunes. Porto Alegre: Ortiz; IEE, 1991.

ROSA, João Guimarães. Grande Sertão: Veredas. 22. ed. São Paulo: Companhia das Letras, 2019.

SAFATLE, V. Dar corpo ao impossível: o sentido da dialética a partir de Theodor Adorno. Belo Horizonte: Autêntica, 2019. 
